\title{
Modified Space Vector Modulated Z Source Inverter with Effective DC Boost and Lowest Switching Stress
}

\author{
S. Thangaprakash*a and A. Krishnan ${ }^{\mathrm{b}}$ \\ * Department of Electrical Engineering, Sri Shakthi Institute of Engineering and Technology, Tamil Nadu, India \\ ${ }^{b}$ K.S.R. College of Engineering, Tiruchengode, Tamil Nadu, India
}

Received 15 June 2009; accepted 3 October 2009

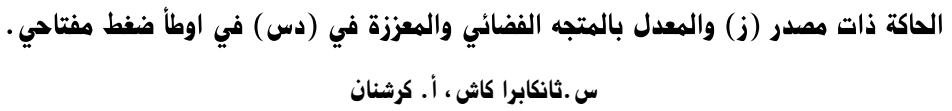

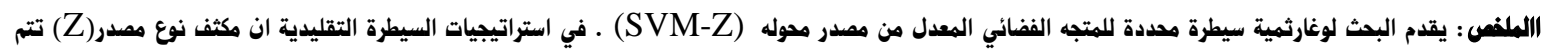

السيطرة عليه في ضربه نسبة الواجب اما المخرجات فتتم السيطرة عليه بواسطة مؤشر التعديل . اللوغارثية الهقترحة توفر متجه فولطية معدل في مسيطر المرحلة الواحدة ويحتوي

على حرية من درجة واحدة بينما السسيطرات التقليدية تحتوي على درجتين من الحرية. في هذه الطريقة من السيطرة يتم الحصول على مدخلات فولطية ربط(دس ) ويتم الحفاظ

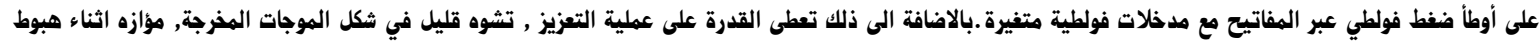

الفولطية والفعف في انسجام الخط. ان خوارزمية السيطرة SVM الهقدمة في هذا البثث قد تم تنفيذها هن خلال Matlab/Simulink وتم تأكيدها تجريبيا خلال

عاكسة بمصدر نوع(Z) في المختبر.

كلمات منتامية: عاكسه بمصدر نوع(Z) ،نبض نوع متجه فضائي ذو عرض معدل (SVPWM) ضغط هفتاحي

\begin{abstract}
This paper presents a modified control algorithm for Space Vector Modulated (SVM) Z-Source inverters. In traditional control strategies, the Z-Source capacitor voltage is controlled by the shoot through duty ratio and the output voltage is controlled by the modulation index respectively. Proposed algorithm provides a modified voltage vector with single stage controller having one degree of freedom wherein traditional controllers have two degrees of freedom. Through this method of control, the full utilization of the dc link input voltage and keeping the lowest voltage stress across the switches with variable input voltage could be achieved. Further it offers ability of buck-boost operation, low distorted output waveforms, sustainability during voltage sags and reduced line harmonics. The SVM control algorithm presented in this paper is implemented through Matlab/Simulink tool and experimentally verified with Z-source inverter prototype in the laboratory.
\end{abstract}

Keywords: Z source inverter, Space vector pulse width modulation (SVPWM), Switching stress

\section{Introduction}

$\mathrm{Z}$ source inverter overcomes the problems in the Traditional Voltage Source and Current Source Inverters. It employs a unique impedance network coupled with the inverter main circuit to the power source. It consists of voltage source from the rectifier supply, impedance network, three phase inverter and three phase load. The ac voltage is rectified to dc voltage by the front end rectifier. The output voltage of the rectifier is 1.35 times the dc input. The rectifier output dc voltage is fed to the impedance network, which consist of two equal inductors $\left(L_{1}=\right.$ $\left.L_{2}=L\right)$ and two equal capacitors $\left(C_{1}=C_{2}=C\right)$. The network inductors are connected in series arms and capacitors are connected in diagonal arms as shown in Fig. 1.

*Corresponding authors’ e-mail: s_thangaprakash@rediffmail.com
The impedance network is used to buck or boost the input voltage depending on the boosting factor derived by applying the shoot through which is to be forbidden in conventional VSIs. This network also acts as a second order filter and it should require less inductance and less capacitance. The inverter main circuit consists of six switches (IGBTs). Z Source inverters use a unique impedance network, coupled between the power source and converter circuit, to provide both voltage buck and boost properties, which cannot be achieved with conventional voltage source and current source inverters. The unique feature of the $\mathrm{Z}$ source inverter is that the output ac voltage can be any value between zero and infinity regardless of dc voltage. That is, the $\mathrm{Z}$ source inverter is a buckboost inverter that has a wide range of voltage control. 


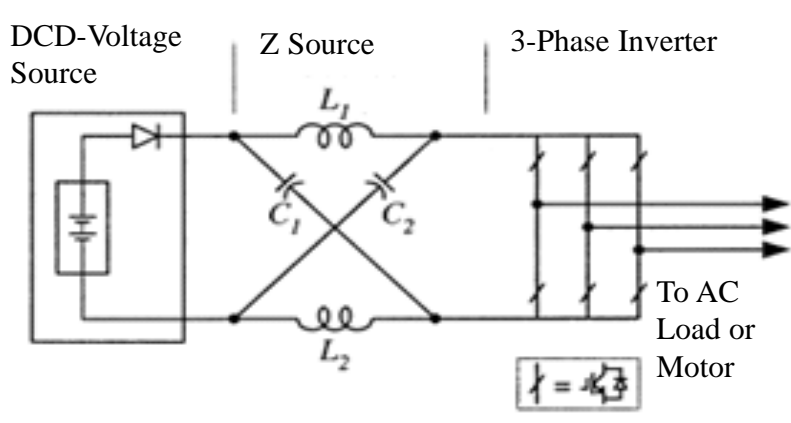

Figure 1. Z-source inverter system

Several control methods for the $\mathrm{Z}$ source inverter have been developed since the $\mathrm{Z}$ source inverter was proposed in 2002. In these control strategies, the capacitor voltage is controlled by the shoot-through duty ratio and the output voltage is controlled by the modulation index, respectively. Both of the two controllers are designed separately, thus the whole system stability is not guaranteed. Furthermore, it cannot make full use of the dc input voltage, which results in low control voltage margin and quite high voltage stress across the switches. The voltage boost is inversely related to the shoot through duty ratio, therefore the ripple in shoot through duty ratio will result in ripple in the current through the inductor as well as the voltage in the capacitor. When the output frequency is low, the inductor current ripple becomes significant. All the above problems are addressed by different control techniques with various control algorithms.

To address the different requirements mentioned above simultaneously, this paper presents a modified voltage vector for the $\mathrm{Z}$ source inverters based on Space Vector PWM techniques, which is composed of the traditional voltage vector and the unique boost factor of the $\mathrm{Z}$ source inverter. Proposed modified control algorithm provides full utilization of the dc link input voltage and lowest voltage stress across the switches when the variable input voltage is applied.

\section{Operation of $\mathrm{Z}$ Source Inverter}

The operating principle and conventional control methods of the $\mathrm{Z}$ source inverter are discussed in (Fang Zheng Peng, 2003). The traditional three-phase voltage source inverter has six active vectors in which the dc voltage is impressed across the load and two zero vectors when the load terminals are shorted through either the lower or upper three devices, respectively. However, three phase Z source inverter bridge has one extra zero state called shoot through, when the load terminals are shorted through both the upper and lower devices of any one phase leg, any two phase legs, or all three phase legs. This shoot-through zero state is forbidden in the traditional voltage source inverter, because it would cause a shoot-through. The $\mathrm{Z}$ source network makes the shoot-through zero state efficiently utilized throughout the operation. Equivalent circuit of the $\mathrm{Z}$ source inverter could be drawn as shown in Fig. 2. Diode

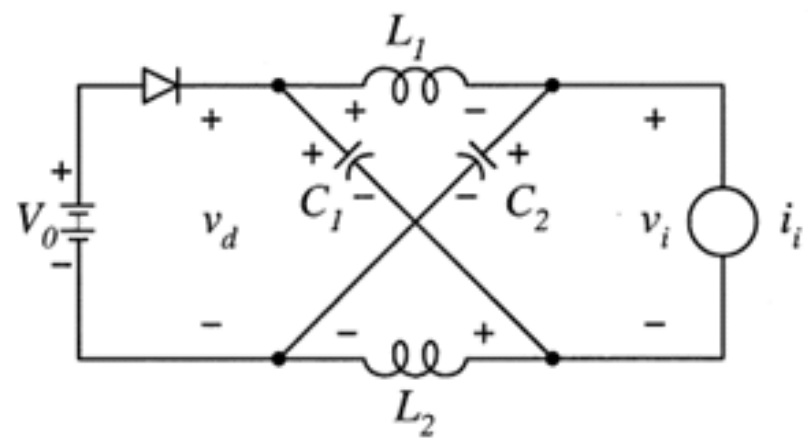

Figure 2. Equivalent circuit of Z-source inverter

is inserted in the equivalent circuit to represent the unidirectional power flow. It has three operating modes, namely traditional zero mode, shoot through mode and nonshoot through mode. Assuming that the inductors $L_{1}$ and $L_{2}$ and capacitors $C_{1}$ and $C_{2}$ have the same inductance $(L)$ and capacitance $(C)$ respectively,

From the symmetry of the $\mathrm{Z}$ source network and equivalent circuit we have,

$$
V_{C 1}=V_{C 2}=V_{C} ; \quad v_{L 1}=v_{L 2}=v_{L}
$$

Mode I - The inverter bridge is under shoot through state for an interval $T_{0}$, during a sampling period $T_{s}$. The diode in the equivalent circuit will be reverse biased in this case. The voltage across the impedance elements could be related as,

$$
v_{L}=V_{C} ; v_{d}=2 V_{C} ; \quad v_{i}=0
$$

Where $v_{d}$ the dc voltage before the impedance is network and is the dc link voltage of the inverter.

Mode - II - The circuit is in any one of the active vectors thus operating in one of the non shoot through state for an interval of $T_{1}$, during the switching cycle $T_{s}$. The diode in the equivalent circuit will be forward biased in this case. From the symmetry of the $\mathrm{Z}$ source network and equivalent circuit we have,

$$
\begin{aligned}
& v_{L}=V_{0}-V_{C} ; v_{d}=V_{0} \\
& v_{i}=V_{C}-v_{L}=V_{C}-V_{0}
\end{aligned}
$$

Where $V_{0}$ is dc supply voltage and $T=T_{0}+T_{1}$.

Mode III - The inverter bridge is in any one of the traditional zero vectors (000 or 111) thus operating in one of the traditional zero vector mode.

The average voltage of the inductors over one switching Period $\left(T_{s}\right)$ should be zero in steady state, from (2) and (3) we have,

$$
V_{L}=\overline{v_{L}}=\frac{T_{0}+T_{1}\left(V_{0}+V_{c}\right)}{T_{s}}=0
$$

\section{Or}

$$
\frac{V_{c}}{V_{0}}=\frac{T_{1}}{T_{1}-T_{0}}
$$


Similarly the average dc link voltage across the inverter bridge can be found as follows,

$$
V_{i}=\overline{v_{i}}=\frac{T_{0} * 0+T_{1} *\left(2 V_{c}-V_{0}\right)}{T_{s}}=\frac{T_{1}}{T_{1}-T_{0}} \cdot V_{0}=V_{c}
$$

The peak dc link voltage across the inverter bridge is expressed in (3) and it can be written as,

$$
\hat{v}_{i}=V_{C}-v_{L}=2 V_{C}-V_{0}=\frac{1}{1-2 D_{0}} V_{0}=B V_{0}
$$

Where, $D_{0}=\frac{T_{1}}{T_{1}-T_{0}}=$ Shoot through duty ratio and B is boost factor. The voltage stress $V_{s}$ across the switch is equal to the peak dc-link voltage $\hat{v}_{i}=B V_{0}$. Therefore, to minimize the voltage stress for any given voltage gain $\left(G=B \cdot m_{a}\right)$, we need to minimize $B$ and maximize modulation index $\left(m_{a}\right)$ with the restriction of that their product is the desired value. On the other hand, we should maximize $B$ for any given modulation index $m_{a}$, to achieve the maximum voltage gain.

The basic idea of control is to turn traditional zero state into shoot-through zero state, while keeping the active vectors unchanged, thus we can maintain the sinusoidal output and at the same time achieve voltage boost from the shoot through of the dc link. To achieve good performance for both the dc boost and the ac output voltage in the $\mathrm{Z}$ source inverter, several close-loop control methods were proposed. In these control methods, the capacitor voltage is controlled by the shoot-through duty ratio $D_{o}$ and the output voltage is controlled by the modulation index $m_{a}$ respectively. The two degree-of-freedom controllers are designed separately. It has some inherent drawbacks.

\section{Modified Modulation Technique}

\subsection{Space Vector Modulation}

SVPWM method is an advanced, Computation-intensive PWM method and is possibly the best among all the PWM techniques for variable speed applications. Because of its superior performance characteristics, it has been finding widespread application in recent years. All the existing PWM methods have only considered implementation on a half bridge of a three phase bridge inverter. If the load neutral is connected to the center tap of the dc supply, all three bridges operate independently, giving satisfactory PWM performance. With the machine load, the load neutral is normally isolated, which causes interaction among the phases. This interaction was not considered in other PWM techniques. SVPWM considers this interaction of the phases and optimizes the harmonic content of the three phase isolated neutral load. There are not separate modulation signals in each of the three phases in SVPWM techniques. Instead, a voltage vector is processed as a whole. Therefore, it is very suitable to control the shoot-through time. Figure 3 the discontinuous inner circle shows the trajectory of voltage space vectors ( $V$ ) for the traditional three-phase two-level PWM inverters.

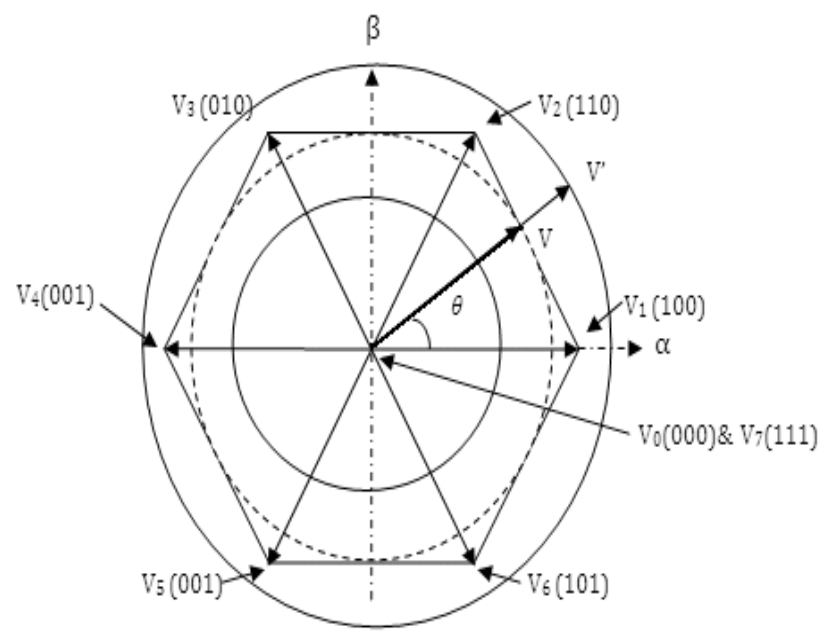

Figure 3. Voltage space vectors with shoot through states for $\mathrm{Z}$ source inverter

The output voltage of the inverter is determined by the different voltages between each inverter arm and the time duration in which the different voltage is maintained. Eight voltage vectors $\vec{V}_{0}, \overrightarrow{V_{1}}, \overrightarrow{V_{2}} \ldots \ldots . \overrightarrow{V_{7}}$ corresponding to the switching states $\overrightarrow{S_{0}}=$ $\left[\begin{array}{lll}0 & 0 & 0\end{array}\right], \overrightarrow{S_{1}}=\left[\begin{array}{lll}1 & 0 & 0\end{array}\right] \ldots \ldots . . . . . \quad \overrightarrow{S_{7}}=\left[\begin{array}{lll}1 & 1 & 1\end{array}\right]$ respectively. $\overrightarrow{V_{1}}$, $\overrightarrow{V_{2}} \ldots \ldots . . \vec{V}_{6}$ are called active vectors $\overrightarrow{V_{0}}$ and $\overrightarrow{V_{7}}$ are called traditional zero vectors.

The length of the active vectors is unity and length of the zero vectors is zero. In one sampling interval $T_{s}$, the output voltage vector of the traditional inverter $\vec{V}$ is split into the two nearest adjacent voltage vectors. These two nearest active vectors and the traditional zero vectors are used to synthesize the output voltage vector. $\overrightarrow{V_{n}}$ and $\overrightarrow{V_{n+1}}$ (Where $n=0 \ldots . .6$ ) vectors are applied at times $T_{1}$ and $T_{2}$ respectively, and zero vectors are applied at $T_{z}$ times. For example in sector $I$, vector $\vec{V}$ can be synthesized as,

$$
\begin{aligned}
& \vec{V}=\frac{T_{1}}{T_{s}} \vec{V}_{1}+\frac{T_{2}}{T_{s}} \vec{V}_{2}+\frac{T_{z}}{T_{s}}\left(\vec{V}_{0} o r \vec{V}_{7}\right) \\
& T_{1}=\frac{2}{\sqrt{3}}|\vec{V}| \cos \left(\theta+\frac{\pi}{6}\right) T_{s} \\
& T_{2}=\frac{2}{\sqrt{3}}|\vec{V}| \cos \left(\theta+\frac{3 \pi}{2}\right) T_{s} \\
& T_{z}=T_{s}-T_{1}-T_{2}=\left(1-\frac{2}{\sqrt{3}}|\vec{V}| \cos \left(\theta+\frac{\pi}{3}\right) T_{s}\right)
\end{aligned}
$$


Where $2 n \pi \leq \theta=w t \leq 2 n \pi+\frac{\pi}{3}$

The trajectory of voltage vector $\vec{V}$ should be a circular while maintaining pure sinusoidal output lineto-line voltages. The boundary of the linear modulation and over modulation is the hexagon. The time duration for the active vectors are kept constant throughout the operation and the zero vector time is conveniently placed depending upon the angle of the space vector $\left(T_{z}\right.$ is decreased when voltage vector is increased). The maximum output line-to-line voltage is obtained when the voltage vector trajectory becomes the inscribed circle of the hexagon and $|\vec{V}|$ becomes $\frac{\sqrt{3}}{2}$. This limitation of the length of the active vector affects the smooth operation of loads like motor drives where overdrive is desired.

\subsection{Modified Space Vector Modulation for ZSI}

For a three-phase-leg two level VSI, both continuous switching (eg. centered SVM) and discontinuous switching (eg. 60 -discontinuous PWM) are possible with each having its own unique null placement at the start and end of a switching cycle and characteristic harmonic spectrum. The same strategies with proper insertion of shoot through modes could be applied to the three-phase-leg Z source inverter with each having the same characteristic spectrum as its conventional counterpart. There are fifteen switching states of a three-phase-leg z-source inverter. In addition to the six active and two null states associated with a conventional VSI, the Z source inverter has seven shoot-through states representing the short-circuiting of a phase-leg $\left(E_{1}\right)$, two phase-legs $\left(E_{2}\right)$ or all three phase-legs $\left(E_{3}\right)$. These shoot-through states again boost the dc link capacitor voltages and can partially supplement the null states within a fixed switching cycle without altering the normalized volt-sec average, since both states similarly short-circuit the inverter three-phase output terminals, producing zero voltage across the ac load. Shoot-through states can therefore be inserted to existing PWM state patterns of a conventional VSI to derive different modulation strategies for controlling a three-phase-leg Z-source inverter.

The continuous centered SVM state sequence of a conventional three-phase-leg VSI, where three state transitions occur (e.g., null (000) $\rightarrow$ active(100) $\rightarrow$ active $(110) \rightarrow$ null(111) ) and the null states at the start and end of a switching cycle $T_{s}$ span equal time intervals to achieve optimal harmonic performance. With threestate transitions, three equal-interval $\left(\frac{T_{0}}{3}\right)$ shootthrough states can be added immediately adjacent to the active states per switching cycle for modulating a $\mathrm{Z}$ source inverter where $T_{0}$ is the shoot-through time period in one switching cycle.

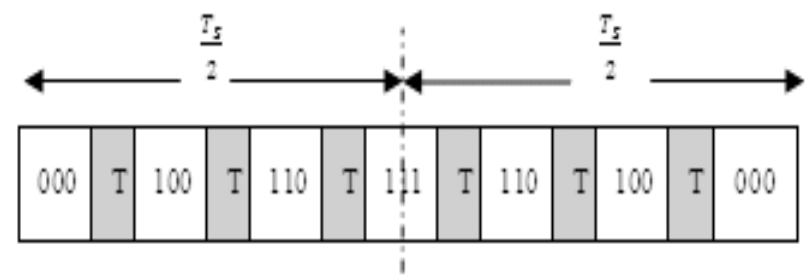

Figure 4. Traditional switching pattern for $\mathrm{Z}$ source inverter

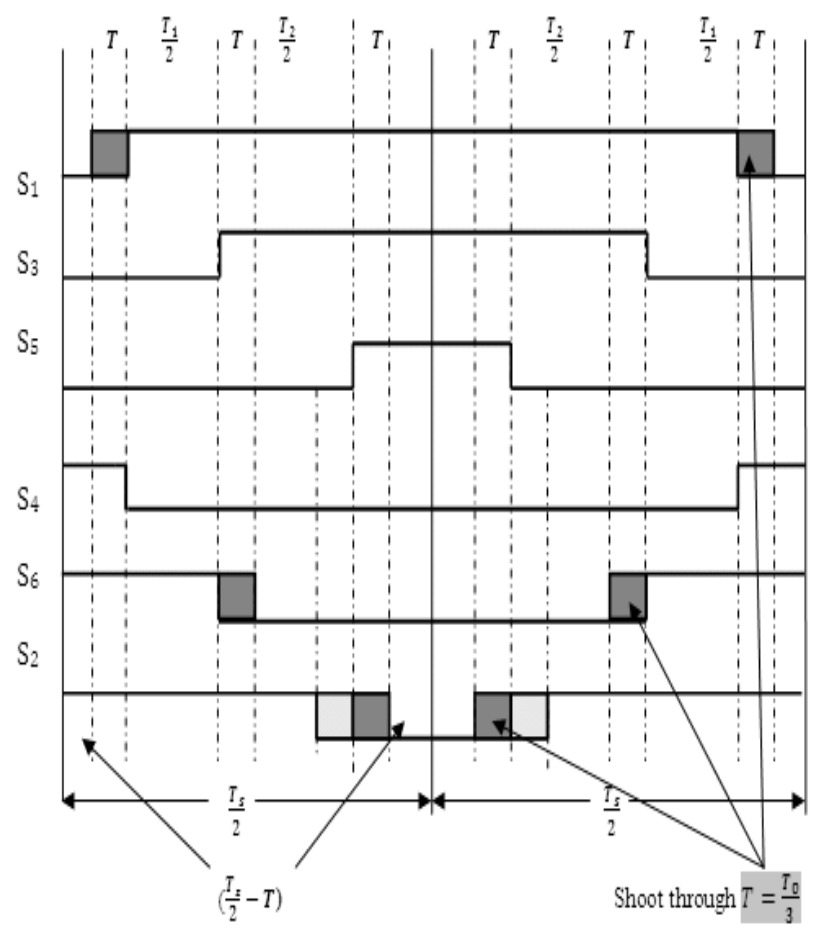

Figure 5. Modified switching pattern for sector 1 to $\mathrm{Z}$ source inverter

Preferably, the shoot-through states should be inserted such that equal null intervals are again maintained at the start and end of the switching cycle to achieve the same optimal harmonic performance. The middle shoot-through state is symmetrically placed about the original switching instant. The traditional switching pattern for sector-I is shown in Fig.4 and modified switching pattern for sectorI is shown in Fig. 5. The active states $\{100\}$ and $\{110\}$ are left/right shifted accordingly by $\mathrm{T}_{0} / 3$ with their time intervals kept constant, and the remaining two shootthrough states are lastly inserted within the null intervals, immediately adjacent to the left of the first state transition and to the right of the second transition. This way of sequencing inverter states also ensures a single device switching at all transitions, and allows the use of only shoot-through states $E_{1}, E_{2}$, and $E_{3}$. The other shootthrough states cannot be used since they require the switching of at least two phase-legs at every transition. The modulating signal for the modified SVM strategy could be derived from the following equations, 


$$
\begin{aligned}
& V_{\max (s p)}=V_{\max }+V_{\text {off }}+T \\
& V_{\max (s n)}=V_{\max }+V_{\text {off }} \\
& V_{\text {mid (sp) }}=V_{\text {mid }}+V_{\text {off }} \\
& V_{\operatorname{mid}(s n)}=V_{\text {mid }}+V_{\text {off }}-T \\
& V_{\min (s p)}=V_{\text {min }}+V_{\text {off }}-T \\
& V_{\min (s n)}=V_{\min }+V_{\text {off }}-2 T \\
& \{s p, s n\}=\{1,4\},\{3,6\},\{5,2\} \\
& \text { Where } T=\frac{T_{0}}{3} \text { shoot through duty ratio . }
\end{aligned}
$$

\subsection{Modified Voltage Vector}

As aforementioned, the modulation signal produced by the conventional VSI method cannot produce voltage vector beyond $\frac{\sqrt{3}}{2}$ and $Z$ source inverters need two stage controllers separately for boost mode and non-boost mode. A modified control technique is presented in this section to overcome the above limitation and allow the voltage vector to be operated beyond $\frac{\sqrt{3}}{2}$ with single stage controller block. Normally the shoot-through duty ratio is defined as follows,

$$
\begin{aligned}
D_{0} & =\min \left(\frac{T_{z}}{T_{s}}\right) ; \text { for } \theta=0 \rightarrow 2 \pi \\
& =\left(1-\frac{2}{\sqrt{3}}\right)|\vec{V}| \sin \left(\theta+\frac{\pi}{3}\right) T_{s}
\end{aligned}
$$

Further $D_{0}$ could be related with the modulation index $m_{a}$ as,

$$
\begin{aligned}
& D_{0}=1-m_{a} \\
& |V|=\frac{\sqrt{3}}{2} m_{a} ; m_{a}=\frac{2}{\sqrt{3}}|V| \text { then } \\
& D_{0}=1-\frac{2}{\sqrt{3}}|V| ; \\
& B=\frac{1}{1-2 D_{0}}=\frac{1}{\frac{4}{\sqrt{3}}|V|-1}
\end{aligned}
$$

In boost mode of operation, shoot-through periods for shoot-through vector are acquired from the traditional zero vector and are calculated by (16). In non-boost mode of operation, $\mathrm{Z}$ source inverter operates as a traditional VSI and the boost factor $(B)$ constantly equals one. So the new vector, which is accomplished by both the operating modes non-boost as well as boost, could be defined as,

$$
\overrightarrow{V^{\prime}}=B \cdot \vec{V} \text { and }
$$

$$
\overrightarrow{V^{\prime}}=\frac{1}{\frac{4}{\sqrt{3}}|V|-1} \cdot \vec{V} \text {; for boost mode }
$$

$\overrightarrow{V^{\prime}}=\vec{V} \quad$; for non-boost mode

The length of the modified voltage vector $\overrightarrow{V^{\prime}}$ could be extended beyond $\frac{\sqrt{3}}{2}$ with proper placement of shoot-through time as in expressions (9) - (14). Trajectory of the modified space vector $V^{\prime}$ (continuous outer circle) and the switching pa ttern for $\mathrm{Z}$ source inverter are shown in Fig. 3 and Fig. 5, respectively.

\subsection{Modified Control Algorithm}

As mentioned earlier, the operation of $\mathrm{Z}$ source inverter can be divided into two modes: one is nonboost mode and the other is boost mode. In the nonboost mode, the $\mathrm{Z}$ source inverter operates like the traditional three-phase voltage source inverter, the output voltage vector is limited in the range of ( $0 \square \frac{\sqrt{3}}{2}$ ), while operation in the boost mode, with the help of shoot-through zero state (vector) to boost the voltage, the $\mathrm{Z}$ source inverter can overcome the voltage limitation, any voltage vector beyond $\frac{\sqrt{3}}{2}$ can be easily implemented with proper shoot-through time given in (15). In order to implement the modified control technique to have single-stage boost and non-boost controllers the algorithm could be developed as follows.

During non-boost mode of operation (ie. if the length of the modified voltage vector $\left|V^{\prime}\right|$, is less than or equal to $\frac{\sqrt{3}}{2}$ ) the length of the voltage vector is equal to the modified voltage vector and shoot -through time period is zero.

$$
|\vec{V}|=\left|\overrightarrow{V^{\prime}}\right| ; \quad D_{0}=0
$$

In the other case, during boost mode, (ie. If the length of the modified voltage vector $|\vec{V}|$, is beyond $\frac{\sqrt{3}}{2}$ ) the length of the voltage vector is as follows,

$$
|V|=\frac{1}{\frac{4}{\sqrt{3}}\left|V^{\prime}\right|-1} \cdot\left|\vec{V}^{\prime}\right|
$$


and

$$
D_{0}=1-\frac{2}{3}|V|=\frac{2\left|V^{\prime}\right|}{4\left|V^{\prime}\right|-\sqrt{3}}
$$

The implementation of the proposed control algorithm is shown in Fig. 6. It is clearly exposed that, the modified voltage vector $\overrightarrow{V^{\prime}}$ is the output of the PI controller and it determines the system operating mode and corresponding $D_{0}$ and $|\vec{V}|$ according to the algorithm.

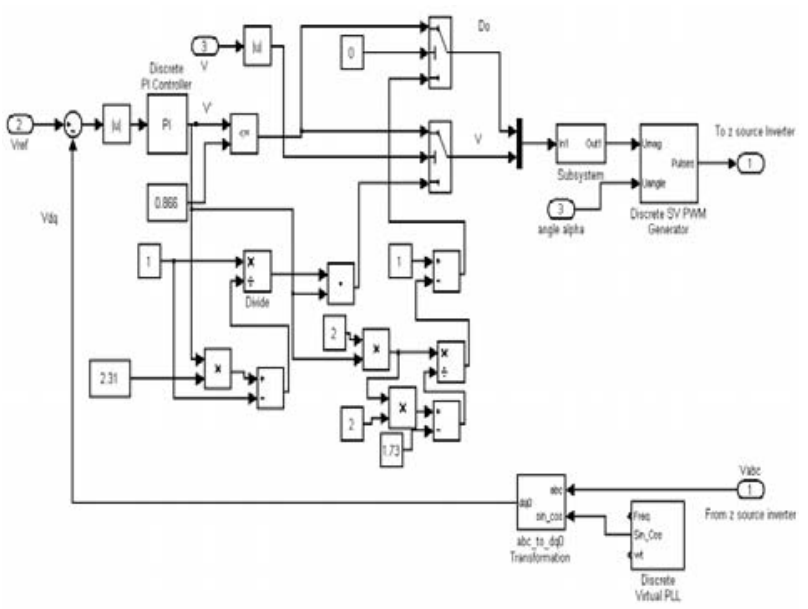

Figure 6. Implementation of the control algorithm

In the $\mathrm{Z}$ source inverter system with the modified control method, only the output voltage needs to be sensed, unlike the traditional control methods that use both the output voltage and the capacitor voltage. The capacitor voltage $V_{c}$ and the dc-link voltage $V_{i}$ are dynamically regulated with the input dc voltage to assure the desired output voltage. When the dc input voltage $V_{o}$ is too low to output the desired voltage $V_{\text {ref }}$ directly, the source inverter will operate in the boost mode to step up the voltage. If, $V_{0}$ is high enough to produce the desired output voltage, the $\mathrm{Z}$ source inverter will operate in the non-boost mode, just like the traditional three phase V-source inverter.

By using the modified control method, output voltage can faithfully follow the reference voltage, and the voltage stress across the switches can maintain minimum regardless of the input voltage.

\section{Results and Discussions}

\subsection{Simulation Results}

The traditional modulation concepts and modified control algorithm based implementation have been verified through simulation by Matlab/Simulink for three bridgetwo level $\mathrm{Z}$ source inverters. The $\mathrm{Z}$ source network has been constructed using existing laboratory components of $L_{1}=L_{2}=L=1 \mathrm{mH}$ and $C_{1}=C_{2}=C=1000 \mu \mathrm{F}$. with the input dc voltage of $150 \mathrm{~V}$ and $f_{s}=5 \mathrm{kHz}$. The simulation results are shown in Figs. 7-9. Modulation signal is generated through the Modified SVPWM technique with mod- ulation index, $m_{a}=0.7 ; \quad m_{f}=100 ;$ shoot-through duty ratio $D_{0}=0.3$ and boost factor $B=2.5$.

Figure 7. shows the modulation signal generated with the presented algorithm through Modified SVPWM technique. Output phase voltage phase current, Voltage across the $\mathrm{Z}$ source capacitors and current through the $\mathrm{Z}$ source inductors of the Traditional control method are depicted in Fig. 8 and the Modified control algorithm based results are depicted in Fig. 9. The output phase voltage and current of the Modified control algorithm is improved significantly and the capacitor voltage (dc link voltage) is efficiently boosted and the voltage ripples across the capacitor and current ripples through the $\mathrm{Z}$ source inductor are reduced considerably.
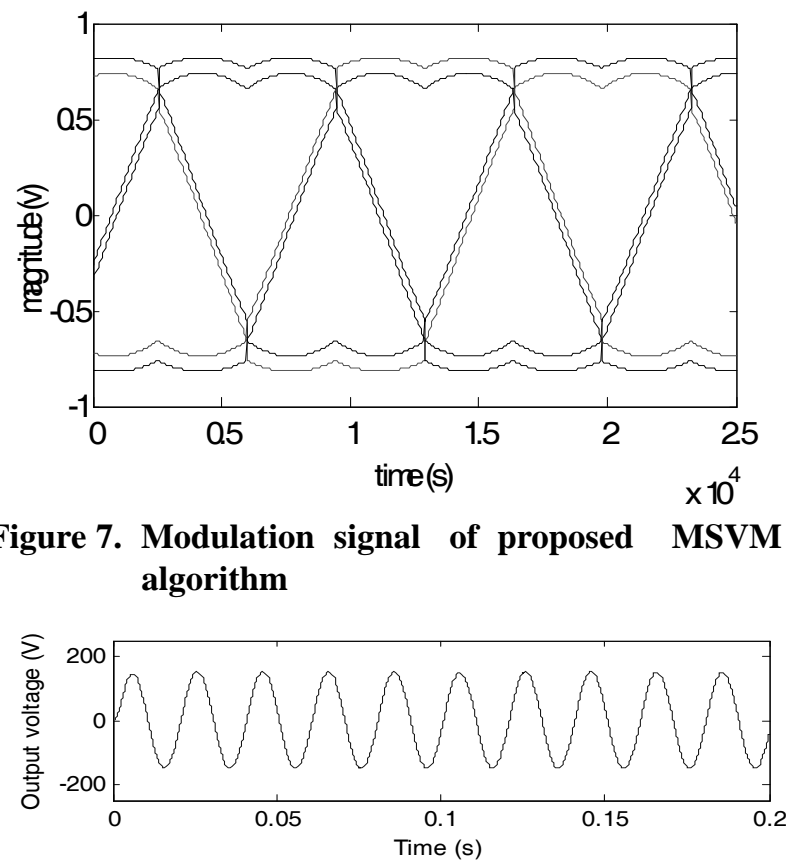

(a)

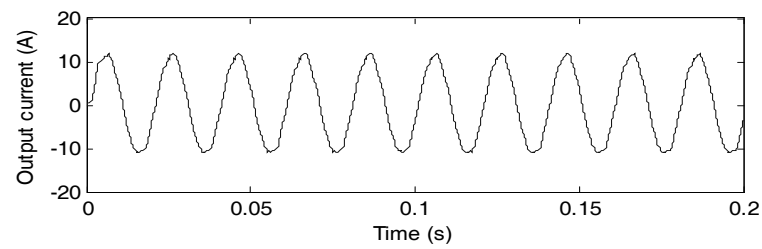

(b)

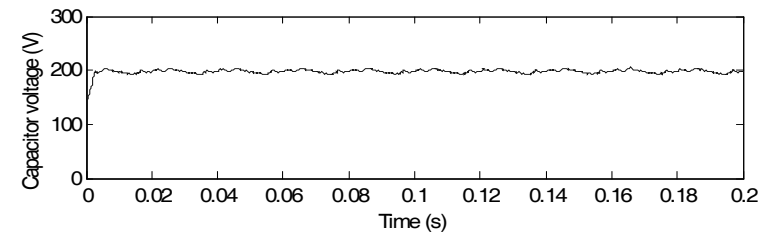

(c)

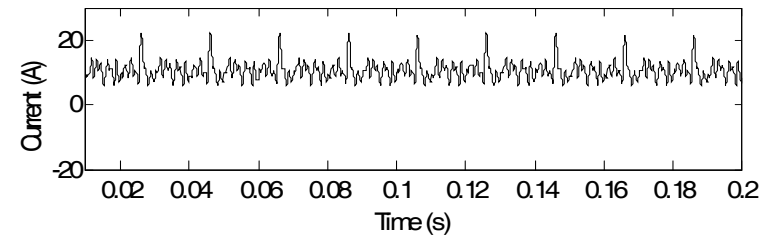

Figure 8. Simulation results of the $\mathrm{Z}$ source inverter with traditional SVPWM a) Output voltage b) Output current c) Z Source capacitor voltage d) Z source inductor current 


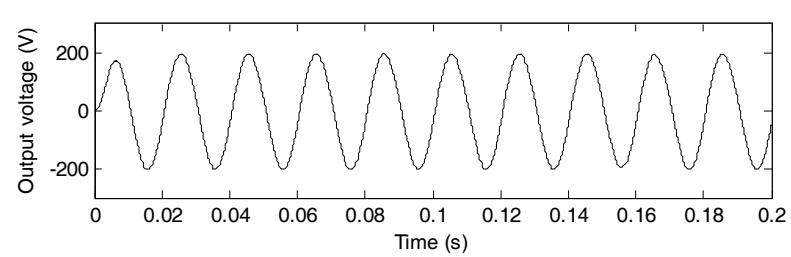

(a)

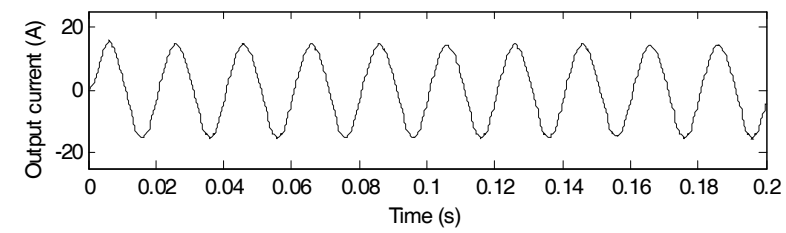

(b)

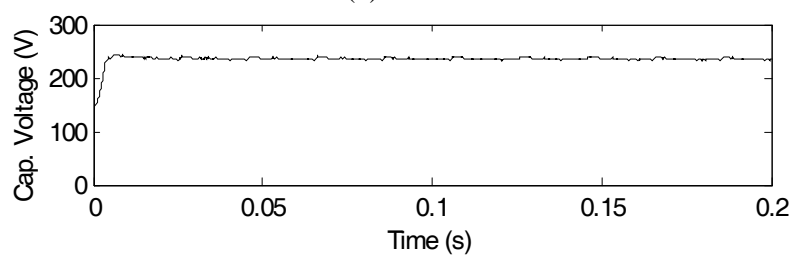

(c)

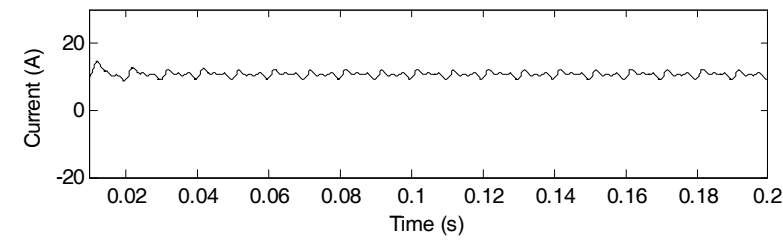

(d)

Figure 9. Simulation results of the $\mathrm{Z}$ source $\mathrm{i}$ nverter with modified SVPWM a) Output voltage b) Output current c) $Z$ source capacitor voltage d) $Z$ source inductor current

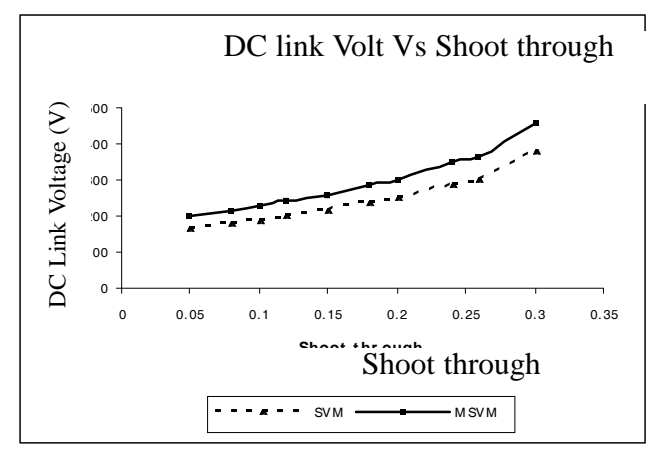

Figure 10. DC link voltage Vs shoot through for traditional SVM and modified SVM

The output phase voltage and current of the Modified control algorithm is improved significantly and the capacitor voltage (dc link voltage) is efficiently boosted (shown in Fig. 10) and the voltage ripples across the capacitor and current ripples through the $\mathrm{Z}$ source inductor are reduced considerably.

\subsection{Experimental Validation}

Experimental verification using a three bridge-two level Z source inverter prototype has been performed to validate the simulation results (shown in Fig. 11). The

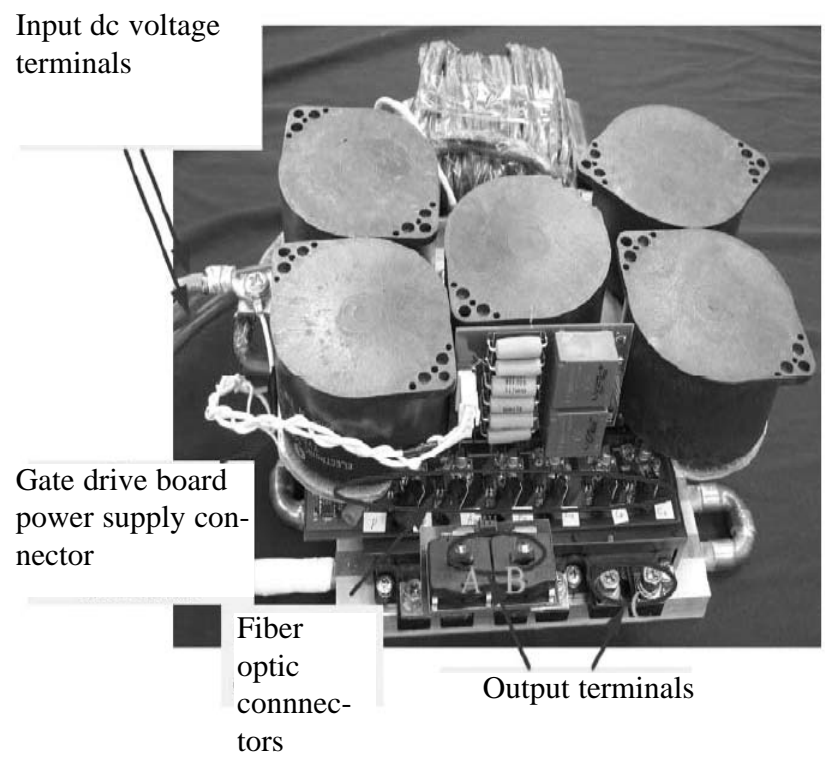

Figure 11. Prototype of $Z$ source inverter

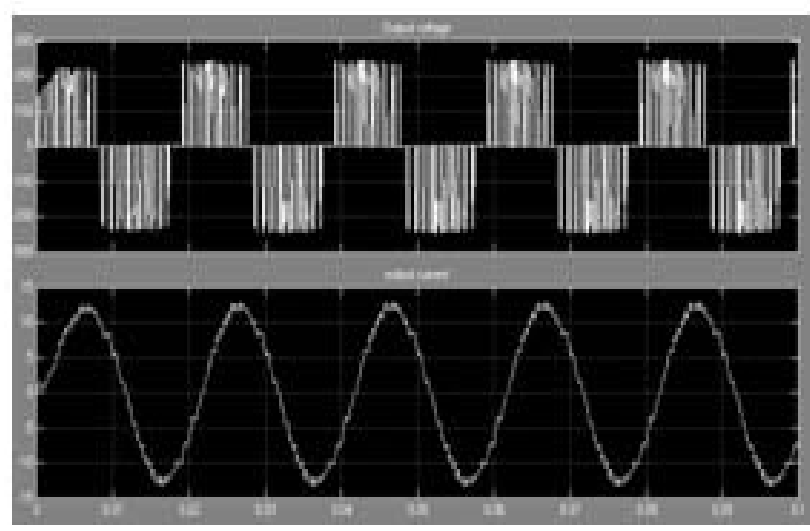

Figure 12. Experimental switching line voltage (upper) and current waveform (lower) of the inverter

hardware inverter is controlled digitally using a Texas Instruments TMS320F240 digital signal processor (DSP) with composed $\mathrm{C}$ codes for generating the required references and a general purpose timer in the DSP for generating the common $5-\mathrm{kHz}$ triangular carrier needed for reference comparison. The DSP generated PWM pulses were then sent out through six independent PWM channels to gate the six switches (IGBT modules) of the implemented inverter.

The experimental switching line voltage and current waveform of the inverter with modulation index $m_{a}=0.7$; shoot-through duration $D_{o}=0.3$; boost factor $B=2.5$ for the $\underline{150} V_{d c}$ with the low-pass $\left(f_{c}=1 \mathrm{kHz}\right) L C$ filter network is shown in Fig. 12.

\section{Conclusions}

This paper presents a novel control algorithm to control the capacitor voltage (boost factor) of the $\mathrm{Z}$ source 
inverter to be operated beyond the modulation $\frac{\sqrt{3}}{2}$ with one degree of freedom. Simulations as well as experimental results are given to validate the algorithm. This presented model greatly reduces the switching stress across the employed power switches (IGBTs). It advantageously utilizes the dc link voltage more effectively than the traditional SVPWM methods. Moreover it has the following advantages

1) Linear control of the output voltage is possible.

2) Automatic changeover of operations from boost mode to buck mode and vice versa according to the variable input voltage.

3) Economical and easy to implement since, the output alone is sensed to control the inverter.

4) Single stage control provides one degree of freedom of controlling the output voltage.

5) It has reduced harmonics, low switching stress power and low common mode noise.

\section{References}

Bimal K. Bose, 2005, "Modern Power Electronics and AC Drives," Prentice Hall of India.

Donald Grahame Holmes, 1996, "The Significance of Zero Space Vector Placement for Carrier based PWM Schemes," IEEE Transactions on Industry Applications, Vol. 32, No. 5, pp. 1122-1129.

Dorin O Neacsu, 2006, "Power Switching Converters: Medium and High Power," Tayler and Francis Group, CRC Press, Boca Raton, FL.

Fang Zheng Peng, 2003, "Z source Inverter," IEEE Trans. Ind.ustry Applications., Vol 39(2), pp. 504-510.

Fang. Z., Peng, M., Shen, A., Joseph, L. M., Tolbert and D. J.Adams, 2004, "Maximum Constant Boost
Control of the Z-Source Inverter," In proeedings. EEE IAS'04, pp. 142-147.

Fang Zheng Peng, Xiamoing yuvan, Xupeng Fang and Zhaoiming Qian, 2005, "Z-Source Inverter for Motor Drives," IEEE Transactions on Power Electronics, Vol. 20(4), pp. 857-863.

Holtz, J., 1992, "Pulse Width Modulation-a Survey," IEEE Transactions on Industrial Electronics, Vol. 39, pp. 410-420.

Jin-Woo and Ali Keyhani, 2007, "Control of a Fuel Cell Based Z source Converter," IEEE Transactions on Energy Conversion, Vol. 22(2), pp. 467-476.

Keliang Zhou and Danwei Wang, 2002, "Relationship between Space Vector Modulation and Three Phase Carrier based PWM: A Comprehensive Analysis," IEEE Transactions on Industrial Electronics, Vol. 49(1), pp. 186-196.

Poh Chiang Loh, Mahintha Vilathgamuwa, Yue sen Lai, Geok Tin Chua and Yun Wei Li, 2005, "Pulse Width Modulation of Z-Source Inverters," IEEE Transactions on Power Electronics, Vol 20(6), pp. 1346-1355.

Quang-Vinh Tran, Tae-Won Chun, Jung-Ryol Ahn and Hong-Hee Lee, 2007, "Algorithms for Controlling Both the DC Boost and AC Output Voltage of ZSource Inverter," IEEE Transactions on Industrial Electronics, Vol. 54(5), pp. 2745-2750.

Shen, M. and F. Z. Peng, 2008, "Operation Modes and Characteristics of the Z-Source Inverter with Small Inductance or Low Power Factor," IEEE Transactions on Industrial Electronics, Vol. 55(1), pp. 89-96.

Sidney R. Bowes and Yen-Shin Lai, 1997, "The Relationship Between Space Vector Modulation and Regular Sampled PWM," IEEE Transactions on Industrial Electronics, Vol. 44(5), pp. 670-679. 